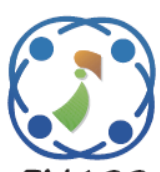

\title{
Novel of Vertical Axis Wind Turbine with Variable Swept Area Using Fuzzy Logic Controller
}

\author{
Jazuli Fadil ${ }^{1,2 *}$ \\ Soedibyo Soedibyo ${ }^{1}$ \\ Mochamad Ashari ${ }^{1}$ \\ ${ }^{1}$ Department of Electrical Engineering, Institut Teknologi Sepuluh Nopember, Surabaya, Indonesia \\ ${ }^{2}$ Department of Electrical Engineering, Politeknik Negeri Banjarmasin, Banjarmasin, Indonesia \\ * Corresponding author's Email: fadiltech2@gmail.com
}

\begin{abstract}
This paper presents a new approach to wind turbine power generation. A vertical axis wind turbine (VAWT) is capable of achieving a constant power output regardless of wind speed, using variable swept area (VSA) as smart rotors which are adjustable for height and width adjusted with actuators. The VSA housing is connected to a permanent magnet synchronous generator (PMSG) and a DC-DC boost converter. The VSA rotors are controlled by a fuzzy logic controller (FLC) to maintain a constant power rating at the PMSG. The variable inputs of FLC are based on wind speed and are then broken down into cluster groups, each of which represents a wind speed range which is assigned a position through the FLC. The cluster groups determine the VSA size which compensates for the non-linear characteristics of the wind speed to get a consistent power rating for the PMSG. The experimental of VSA system is tested with wind speed variation from 0 to $12 \mathrm{~m} / \mathrm{s}$. The VSA velocity movement is limited from $0.75 \mathrm{~m}^{2}$ to $1.87 \mathrm{~m}^{2}$. The VSA extension increase 33\% to tap constant power at 200 Watt when wind speed decreases from 12 to $10 \mathrm{~m} / \mathrm{s}$. The result of proposed method is compared with fixed swept area (FSA), so that the VSA achieved four times increase in efficiency greater than FSA, and the VSA system can be operated at wider range of wind speeds.
\end{abstract}

Keywords: VAWT, Swept area, Variable speed, Telescopic wind turbine, Variable blade.

\section{Introduction}

All Renewable energy has become very attractive in recent decades as a clean energy to replace fossil fuels and reduce environmental crises $[1,2]$. Wind energy is an alternative source for electrical power generation and one of the fastest growing renewable energy resources $[3,4]$. Each design has its merits but the advantages of the VAWT design are hard to overlook due to the fact they can capture wind energy from any direction without using a yaw system like horizontal axis wind turbine (HAWT) $[5,6]$. That in itself is a great benefit as far as manufacturing costs go and coupled with the fact that the generator can be placed perpendicular to the ground making maintenance much easier [7]. Power output from wind turbines depends on three parameters namely wind speed, power coefficient and the swept area [8].

Current research generally uses a fixed swept area, with the control used is a variable pitch control to increase power captured $[9,10]$. The fixed swept area with variable pitch control is conventional technique to improve VAWT power. Research on the fixed size swept area with pitch control of VAWT aiming to improve wind turbine power has been conducted by several researchers. An experiment with a swept area of $1.57 \mathrm{~m}^{2}$ at a wind speed rating of $9 \mathrm{~m} / \mathrm{s}$ indicates that it is capable of producing $114 \mathrm{Watt}$ power output [11]. The research is compared with a mathematical model, where the power generated is $5.9 \%$ is higher than the mathematical model.

Another study with a swept area of $0.30 \mathrm{~m}^{2}$ shows that the maximum power produced is 73 Watt at a wind speed of $11 \mathrm{~m} / \mathrm{s}$ with a fixed pitch angle of $9^{\circ}$ [12]. With a swept area of $0.557 \mathrm{~m}^{2}$, the maximum power produced is $150 \mathrm{Watt}$, capable of increasing turbine efficiency by $16 \%$ with variable pitch control at an optimal angle; thus, this paper uses a collective variable pitch control method [13]. 


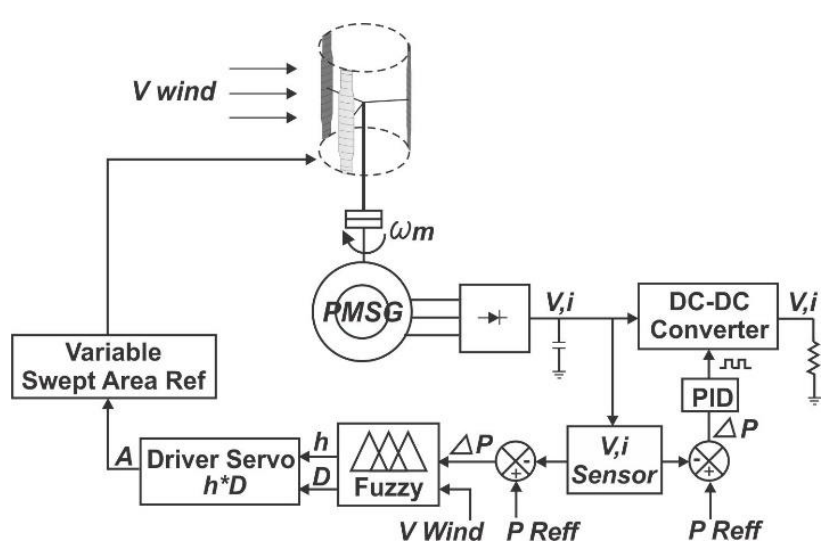

Figure. 1 VAWT control system with VSA

For a swept area of $0.72 \mathrm{~m}^{2}$ with the variable pitch control method, it is tested at wind speed of 10 $\mathrm{m} / \mathrm{s}$, and shows that it can increase the turbine performance by $25 \%$ [14]. The study uses an artificial intelligent of the multilayer perceptron artificial neural network (MLP-ANN) method and PID for pitch angle optimization. It shows that MLP-ANN generates better result than PID. Variable pitch control with artificial intelligent is widely applied as a limiting power output when above the wind speed rating. $[15,16]$.

However, the variable pitch control discussed above cannot maintain constant power when the wind speed is below the wind speed rating because at low wind speed the pitch angle remains at a fixed pitch angle $[16,17]$, and the study uses fixed swept area which means that under that condition the power will fluctuate following changes in wind speed. Then, during storm when the rotor is in parking mode, it is unable to limit loads at high wind speed. This problem can be resolved by reducing the rotor diameter (swept area) at high wind speed, and increasing the swept area rotor at low wind speed to tap constant power using variable swept area.

Passupulaty and Mark Dowson have suggested the idea of a variable swept area or an adjustable rotor blade to increase the power of the wind turbine [18]. This concept has been designed with telescopic blades or smart rotor which are extended when the wind speed falls below the rated level to produce power [18-21]. The focus of this study is to verify that variable length rotors will obtain higher energy at low wind speed and keep the power at constant level. However, this turbine depends on wind direction because it uses horizontal rotor type.

Our previous research on VSA of VAWT discussed increased mechanical power output when below the wind speed rating, and described that the greater the swept area the greater the power produced by VAWT [22]. However, the study merely discussed mechanical power output in a three-stage swept area with control manual without implementing a comprehensive wind turbine power plant model. Since there is not any control applied both in the control side of the rotor and the control side of the generator, the effect of increasing mechanical power on the generator rating to maintain constant power is not yet observable.

This paper presents a novel of VAWT with VSA as shown Fig. 1, in which the swept area adaptively changes based on wind speed variable, so that the efficiency of wind turbine at low wind speed can be improved. The objective of this proposed method is to achieve a constant power output regardless of wind speed, using VSA as smart rotors with FLC at rotor side and PID controller at converter side. The VSA mechanism is adjustable for height and width with actuators. The VSA housing is connected to a permanent magnet synchronous generator (PMSG) and a DC-DC boost converter. The VSA rotors are controlled by FLC to maintain a constant power rating at the PMSG. The variable input of FLC is based on wind speed and is then broken down into cluster groups, each of which represents a wind speed range which is assigned a position through the FLC.

This paper is organized as follows. Section II presents the background concept of VAWT modeling. Section III presents proposed VSA system with FLC. Then, the experimental set-up is shown in section IV. Section $\mathrm{V}$ presents the assessment of the proposed method, and the conclusion is presented in section VI.

\section{VAWT Modeling}

The concept of wind energy conversion is the rotor blade of the VAWT converting wind kinetic power into the mechanical power, then the generator connected on the rotor hub to convert mechanical power into electrical power as shown Fig. 2. According to the Betz limit theory by Albert Betz, mechanical power extracted from the wind kinetic power is formulated as the following:

$$
P m=\frac{1}{2} \cdot \rho \cdot A \cdot v^{3} \cdot C p(\theta, \lambda)
$$

Where $P m$ is mechanical power (Watt), $\rho$ is air density which has a typical density of $1.225 \mathrm{~kg} / \mathrm{m}^{3}, A$ is swept area $\left(\mathrm{m}^{2}\right), v$ is cubic function of wind speed $(\mathrm{m} / \mathrm{s})$, and $C p$ is the function of pitch angle $\theta$ and tip speed ratio (TSR) $\lambda$ that represents the power coefficient of rotor blades which has maximum $C p$, according to Betz is 0.593 [23].

The TSR $\lambda$ is the ratio between the blade tip speed and the actual wind speed [24, 25]. 


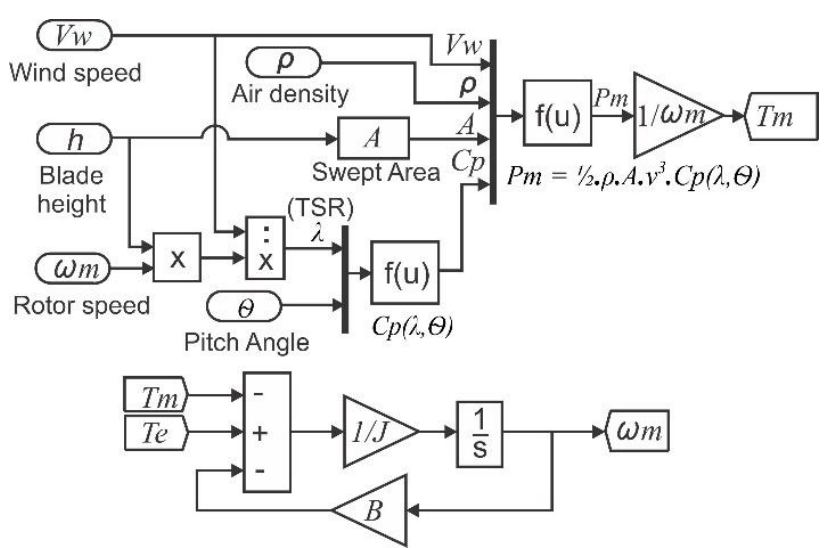

Figure. 2 Wind turbine model

$$
\lambda=\frac{\omega_{m} \cdot r}{v_{w}}
$$

Where $\omega_{m}$ is the angular speed of turbine $(\mathrm{rad} / \mathrm{s}), r$ is the radius of turbine rotor and $v_{w}$ is the wind speed $(\mathrm{m} / \mathrm{s})$. The mechanical angular speed of the rotor and torque can be expressed as follows.

$$
\begin{aligned}
& J \frac{d \omega_{m}}{d t}=T_{e}-T_{m}-B \cdot \omega_{m} \\
& T_{m}=\frac{P_{m}}{\omega_{m}}=\frac{\frac{1}{2} \cdot \rho \cdot A \cdot v^{3} \cdot C p(\theta, \lambda)}{\omega_{m}}
\end{aligned}
$$

Where $T m$ is the mechanical torque of turbine $(N . m)$, $T e$ is the electromagnetic torque $(N . m), J$ is the combined inertia of the wind turbine and rotor $\left(\mathrm{kg} . \mathrm{m}^{2}\right)$, and $B$ is the viscous rotor friction of the rotor (N.m.s/rad). Three primary parameters, i.e. wind speed, swept area, and Cp determine the mechanical power output $[26,27]$. To optimize the mechanical efficiency at different wind speeds, only one suitable rotor speed with maximum $C p$ value with optimum tip speed ratio is available [28].

\section{Proposed VSA system}

VSA has variable height and width rotors fitted to the generator; they can be retracted and extended in accordance with wind speed which is controlled by the Fuzzy logic controller. VSA will affect the power output at the turbine as shown in Eq. (5) and (6). The swept area $A$ is the height of the blade $(h)$ times the turbine diameter $(D)$ as shown in Fig. 3 [22].

$$
A=h \cdot D
$$

Where $h$ is the height of blade and $D$ is the turbine diameter [30]. Hence the VSA can be calculated as follows:

$$
A=(h+\Delta h) \cdot(D+\Delta d)
$$

Where $\Delta h$ and $\Delta D$ are the difference between maximum and minimum position of swept area configuration. Fully extended means the maximum height and diameter of blade when moving outward, while fully retracted means the minimum retraction when retracted. It also applies to the rotor diameter; the position of VSA is determined by wind speed, variable $D$, and variable $h$ as shown in Fig. 4. The calculation of power generated from the turbine is formulated as follows :

$$
P m=\frac{1}{2} \cdot \rho \cdot((h+\Delta h) \cdot(+\Delta D)) \cdot v^{3} \cdot C p(\theta, \lambda)
$$

Where $P m$ is mechanical power (Watt), $\rho$ is air density, $v^{3}$ is cubic function of wind speed $(\mathrm{m} / \mathrm{s})$, and power coefficient $C p$ is the function of pitch angle $\theta$ and tip speed ratio (TSR) $\lambda . \Delta h$ and $\Delta D$ are the difference between maximum and minimum position of swept area configuration.

When the wind speed falls below the generator rating power, the VSA will be extended to obtain appropriate generator power output. If the wind speed increases above the generator rating power, the VSA will be retracted. It becomes the basis of fuzzy logic rule base.

The synthesis of the VSA controller is divided into three zones according to the wind speed value $(v)$ :

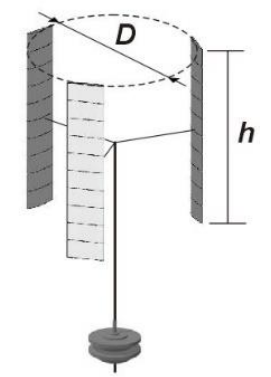

Figure. 3 VAWT swept area

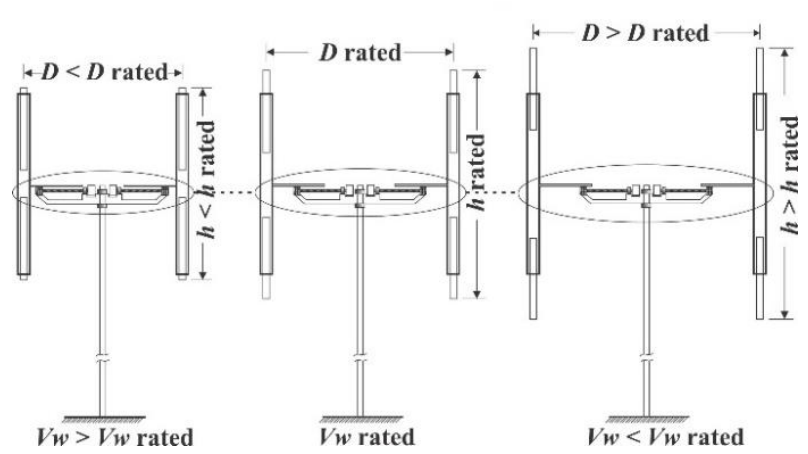

Figure. 4 The VSA rotor concept 
a. Cut-in speed zone: $v<v$ cut-in where VSA changes with variation of variable diameter

b. Tracking speed zone: $v>v$ cut-in $<v$ rating; VSA changes to get optimum power

c. Rated speed zone: $v \geq v$ rating; VSA is retracted to minimum position.

The velocity of VSA, when changed, is adjusted by wind speed clustering as membership function input of Fuzzy Logic controller. The system uses linguistic variables instead of mathematical models of a dynamic system [31, 32]. The block diagram of VSA using FLC can be seen in Fig. 5. For the fuzzification process, membership function is assigned to the linguistic variables [33]. In order to carry out the process, the input variable range is transformed to the wind speed cluster and the input values are transformed to the verbal values. The wind speed clusters are divided into five fuzzy subsets comprising very low (VL), low (L), rating (R), strong (S), and very strong (VS) as shown in Fig. 6, the triangle function is used as the membership function [34].

Table 1. VAWT Parameter

\begin{tabular}{|l|l|}
\hline Parameter & \multicolumn{1}{|c|}{ Value } \\
\hline Rated mechanical power & 1000 Watt \\
\hline Number of Blade & 3 \\
\hline Diameter minimum & $75 \mathrm{~cm}$ \\
\hline Diameter maximum & $125 \mathrm{~cm}$ \\
\hline Blade height minimum & $100 \mathrm{~cm}$ \\
\hline Blade height maximum & $150 \mathrm{~cm}$ \\
\hline Blade type & Lenz \\
\hline
\end{tabular}

Table 2. Fuzzy input

\begin{tabular}{|c|c|c|c|}
\hline Mf & $\begin{array}{c}\text { Wind } \\
\text { Speed }(\mathbf{m} / \mathbf{s})\end{array}$ & Power $(\mathbf{W})$ & $\begin{array}{c}\text { Fuzzy } \\
\text { State }\end{array}$ \\
\hline Cluster 1 & {$[0-6.25]$} & {$[0-468.75]$} & $\begin{array}{c}\text { Very } \\
\text { Low }\end{array}$ \\
\hline Cluster 2 & {$[2.5-10]$} & {$[187.5-750]$} & Low \\
\hline Cluster 3 & $\begin{array}{c}{[6.25-} \\
13.75]\end{array}$ & {$[468.7-1031.2]$} & Rating \\
\hline Cluster 4 & {$[10-17.5]$} & {$[750-1312.5]$} & Strong \\
\hline Cluster 5 & {$[13.75-20]$} & {$[1031.2-1500]$} & $\begin{array}{c}\text { Very } \\
\text { Strong }\end{array}$ \\
\hline
\end{tabular}

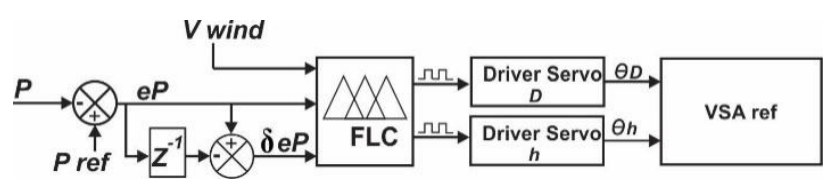

Figure. 5 The VSA control block diagram

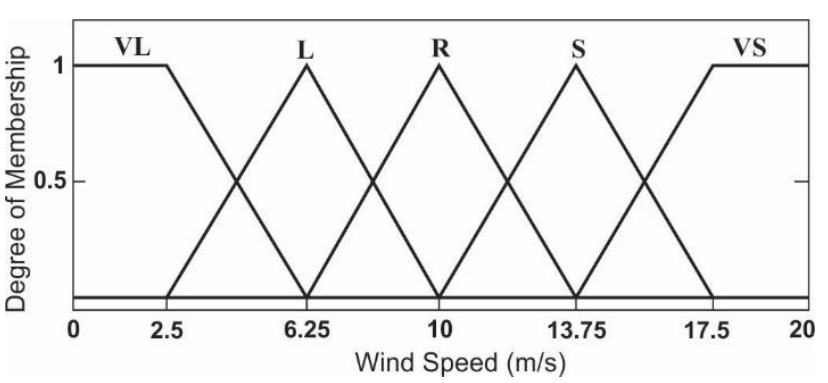

Figure. 6 Membership function of wind speed

After setting up the fuzzy input, the formation of fuzzy rules base is carried out with 25 number of "ifthen" rules. The fuzzy logic rules are modified on the basis of the human experience and expressed through the language variables $[35,36]$. In this paper, defuzzifier using the center of gravity method with the blurring rule base is processed by inference system using the Mamdani method. The result of rules VSA reference is determined by considering fuzzy rules as following:

Rules $_{i}$ : if $v_{w}$ is $A_{i}$ and $e P$ is $B_{i}$ and $\delta e P$ is $C_{i}$, Then $V S A_{\text {ref }}$ is $F_{i} ; \mathrm{i}=1, \ldots, m$

Where $v_{w}$ is wind speed, $e P$ is error in the power output, $\delta e P$ is the delta error power output as shown in Fig. 5, while $A_{i}, B_{i}, C_{i}$ are the fuzzy set and $F_{i}$ is fuzzy singleton. The wind speed and the error power output $e P$ and the delta error power output $\delta e P$ are considered as the input of controller, with the following equations:

$$
\begin{aligned}
& e P(k)=P(k)-P_{r e f}(k) \\
& \delta e P=e P(k)-e P(k-1)
\end{aligned}
$$

The difference of error power input $\delta e P$ is obtained from recent value $e P$ minus with the previous error as shown in Eq. 9. The VSA reference is obtained as a controller output as shown Fig. 5, where $Z^{-1}$ is the sampling time delay.

To tap constant voltage when the wind speed keeps changing, the VAWT is connected to the power converter on its PMSG as shown in Fig. 7. The power converter is made up of an unregulated diode rectifier that converts the AC voltage to DC voltage [37]. The boost converter is connected to the resistive load. It is assumed that all the electronic part components are ideal, such as capacitor for the equivalent series resistance and inductance are ideal or pure capacitance. The DC-DC boost converter with a PID controller will produce duty cycles to generate pulses on IGBT(s) with a certain period as required by the 


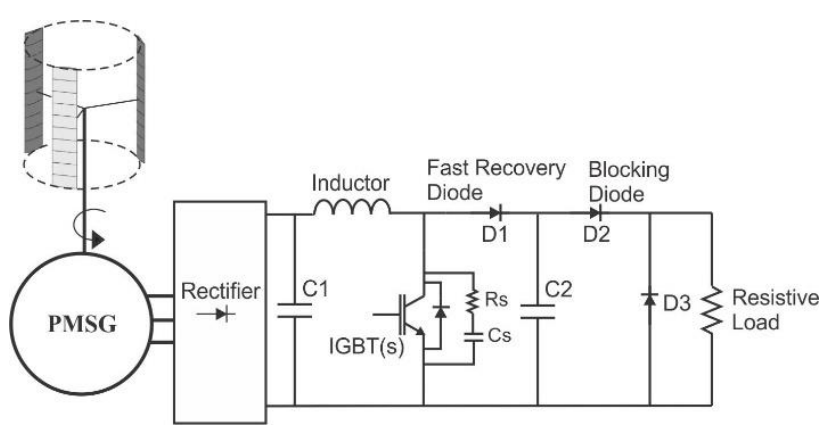

Figure. 7 Boost converter block diagram

Table 3. Parameter of boost converter

\begin{tabular}{|l|c|}
\hline \multicolumn{1}{|c|}{ Parameter } & Value \\
\hline Input Voltage & 35 Volt \\
\hline Output Voltage & 70 Volt \\
\hline Boost Inductor & $92 \mu \mathrm{H}$ \\
\hline Filter Capacitor & $378 \mu \mathrm{F}$ \\
\hline Resistive Load & $25 \mathrm{ohm}$ \\
\hline $\mathrm{Kp}$ & 0.001 \\
\hline $\mathrm{Ki}$ & 0.01 \\
\hline
\end{tabular}

desired design to control the converter circuit switching process $[38,39]$. The duty cycle is defined as the ratio between the switch time on the Ts period [40]. Usually expressed as percentage, the ratio of duty cycle can be written as follows.

$$
D_{c l}=\frac{T_{o n}}{T_{s}} 100 \%
$$

Where $T_{o n}$ is time "on" when transistor switched on, $T_{s}$ is the switching period, and $D_{c l}$ is duty cycle.

The DC-DC boost converter has an output DC voltage greater than the input DC voltage [41]. When the IGBT(s) switch is on, the diode is in a reverse bias, and the output is separated from the input and provides the inductor with energy. When the switch is switched off, the diode is in the forward bias and the energy from the inductor is released through the diode to the load [42]. The voltage output will be higher than the voltage input, because the voltage output is the sum of the voltage input and the inductor voltage [43]. The inductor voltage in a period (Ts) is zero, and depends on the duty cycle that can be written as:

$$
D_{c l} \cdot V_{d c}+\left(1-D_{c l}\right)\left(V_{d c}-V_{\text {out }}\right)=0
$$

Where $V_{d c}$ is the input voltage of the boost converter from rectifier output voltage. $V_{\text {out }}$ is the output voltage of the boost converter. The voltage input and output can be written as:

$$
V_{o u t}=\frac{V_{d c}}{1-D_{c l}}
$$

Where $D_{c l}$ is duty cycle of the converter with ratio times "on" and "off" which can only take on value between 0 and 1 , alternately. The power supplied to the resistive load will be obtained as follows:

$$
P_{\text {out }}=\frac{V_{\text {out }}^{2}}{R_{L}}
$$

Where $R_{L}$ is the resistive load.

$$
P_{o u t}=\frac{V_{d c}^{2}}{\left(1-D_{c l}\right)^{2} R_{L}}
$$

The input power $\left(P_{\text {in }}\right)$ is equal to output power $\left(P_{\text {out }}\right)$ by neglegting the losses of power converter.

$$
P_{\text {in }}=\frac{V_{d c}^{2}}{R_{\text {in }}} \cong P_{\text {out }}=\frac{V_{d c}^{2}}{\left(1-D_{c l}\right)^{2} R_{L}}
$$

Where $R_{\text {in }}$ is the input resistance of boost converter. To maintain constant power, the DC-DC converter uses PID controller and the equation is written as [44] :

$$
u(t)=K_{p} e(t)+K_{i} \int_{0}^{t} e(\tau) d(\tau)+K_{d} \frac{d e(t)}{d t}
$$

Where,

$K_{p}$ is the proportional gain

$K_{i}$ is the integral gain

$K_{d}$ is the derivative gain

$e(t)$ is the error of system

$\tau$ is the integral variable (from time 0 to present $t$ )

The transfer function of the controller is written as:

$$
C(s)=K_{p}+\frac{K_{i}}{S}+K_{d} s
$$

Where $s$ is the complex frequency.

\section{Experimental set-up}

The embodiment of VSA, according to Fig. 8, explains the arrangement of main equipment on this research. The wind speed as variable input used a fan with a capacity from 0 to $20 \mathrm{~m} / \mathrm{s}$ can be applied. The VSA rotor as the essential task of wind energy conversion process consists of height and diameter variable as shown Fig. 9. In which the blade variable can either extend or retract based on the wind speed, so can the diameter variable. The extend and retract mechanism uses servo motor. 


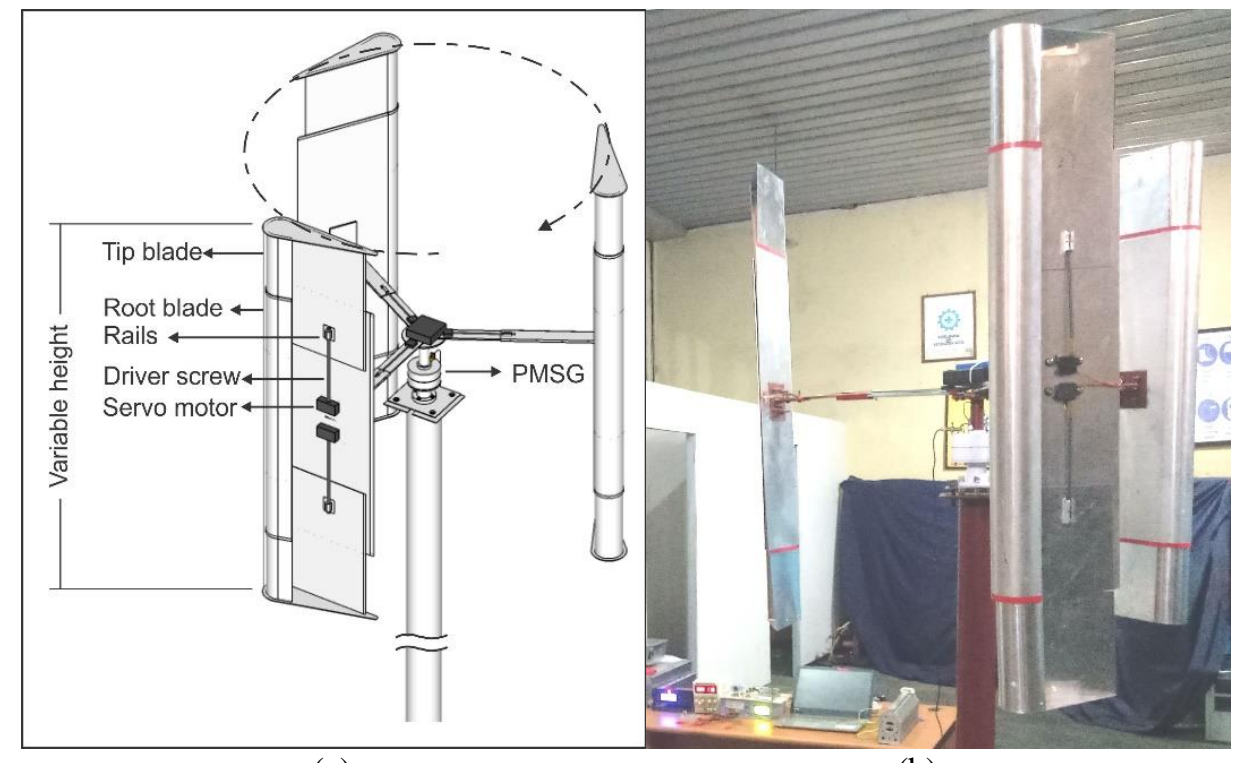

(a)

(b)

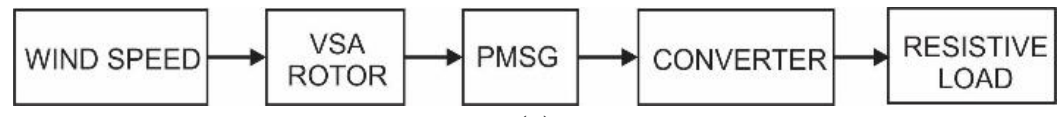

(c)

Figure. 8 (a) The feature of VSA rotor, (b) actual photograph of VSA rotor, and (c) block diagram of main equipment arrangement

The placement of the generator (PMSG) is in between the VSA and the power converter, in which the VSA rotor hub is mounted to the shaft PMSG rotor, the PMSG output connected to the power electronic components such us three phase rectifier, capacitor, converter, and resistive load as shown Fig. 7. The output of rectifier was connected to the boost converter controlled by PID controller to tap constant voltage.

The control system of VSA has two parts: power controller (converter) and rotor controller (Servo driver). Power controller is placed at the base of the turbine, while the rotor controller is placed on the turbine rotor as shown Fig. 9. The communication between power controller and rotor controller is through wireless communication interface.

The rotor controller obtains the signal data from power controller to take appropriate action and track the height of blades and turbine diameter. The rotor controller uses microcontroller to implement the FLC and drive the servo motors to adjust the VSA movement. The adjustment ranges from changes in blade height and diameter length based on wind speed as FLC input. The FLC output was reference of VSA to tap constant power.

The data input and output are recorded by data logger received from the wind speed sensor, proximity sensor, current sensor, and voltage sensor.
Data logger and instruments support can be seen in Fig.10.

The experiment of VSA was as shown Fig. 11 carried out on different swept area extensions, that is extended maximum at $1.87 \mathrm{~m}^{2}$, intermediate at 1,24 $\mathrm{m}^{2}$, and retracted minimum at $0.82 \mathrm{~m}^{2}$, dan tested at varied wind speeds from $1 \mathrm{~m} / \mathrm{s}$ to $19 \mathrm{~m} / \mathrm{s}$, respectively.

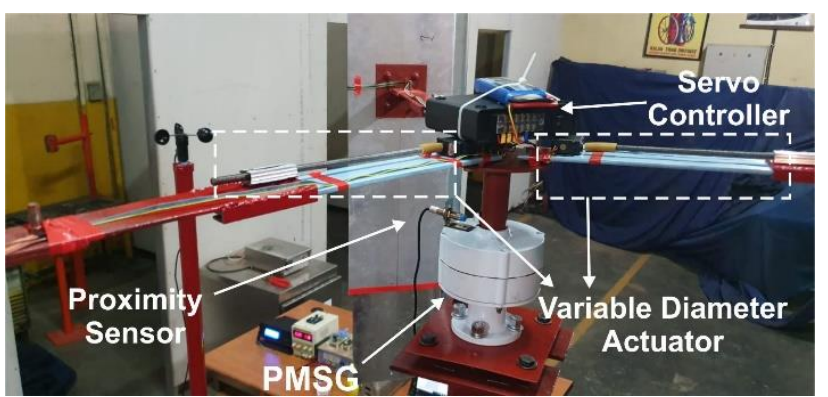

Figure. 9 Variable diameter

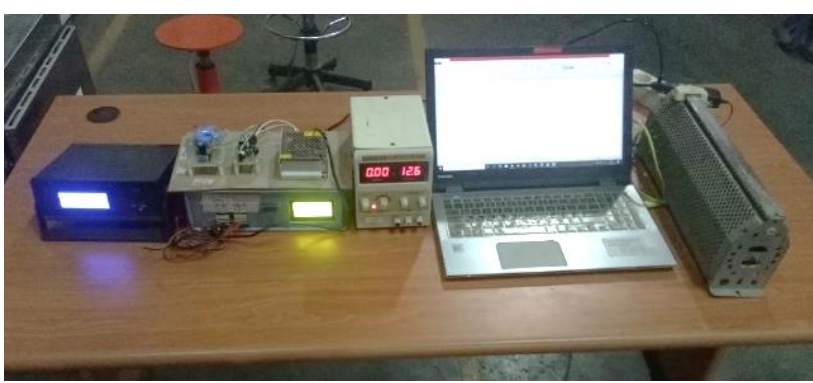

Figure. 10 Data logger and instruments support 


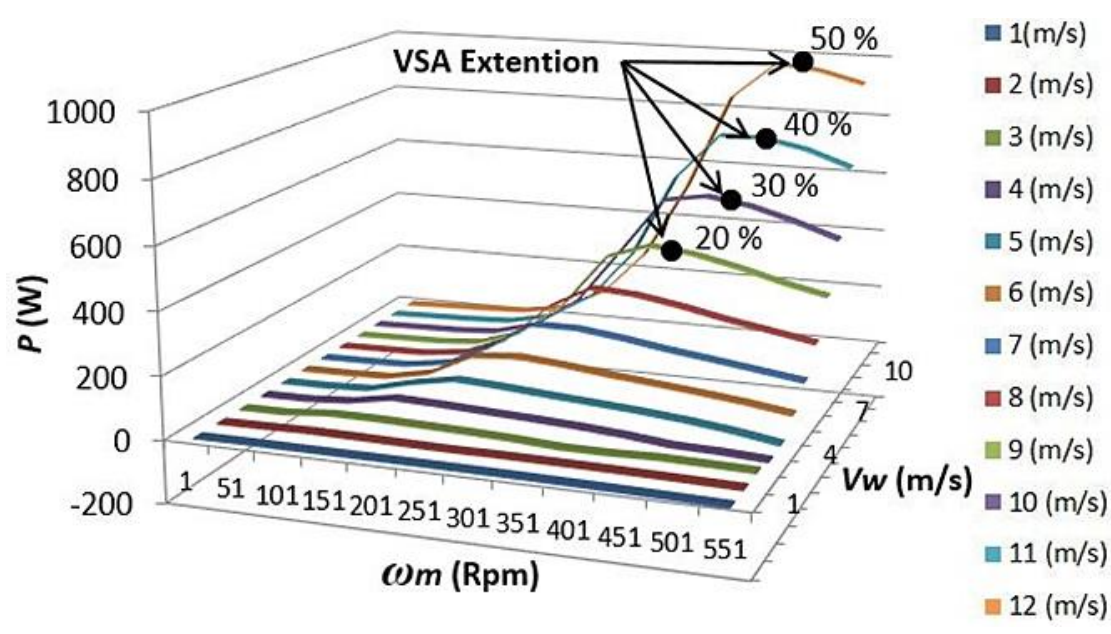

Figure. 12 Power curve of VSA extension

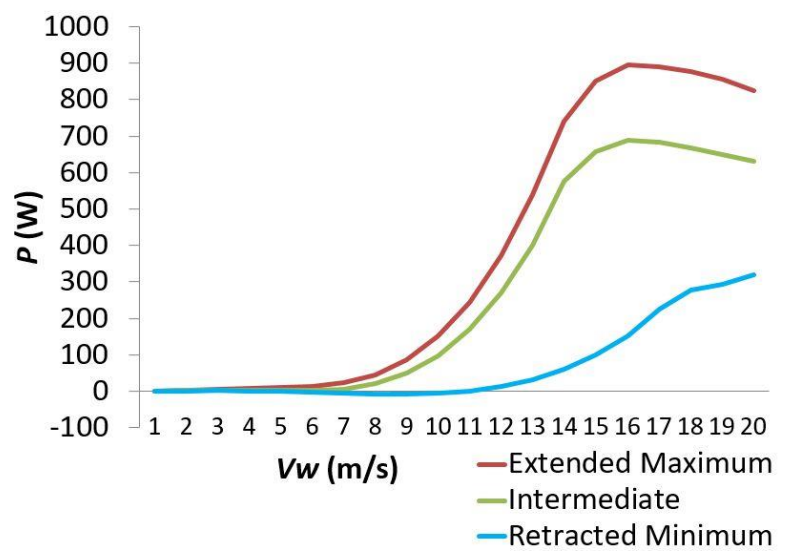

Figure. 11 Power curve of VSA in three position

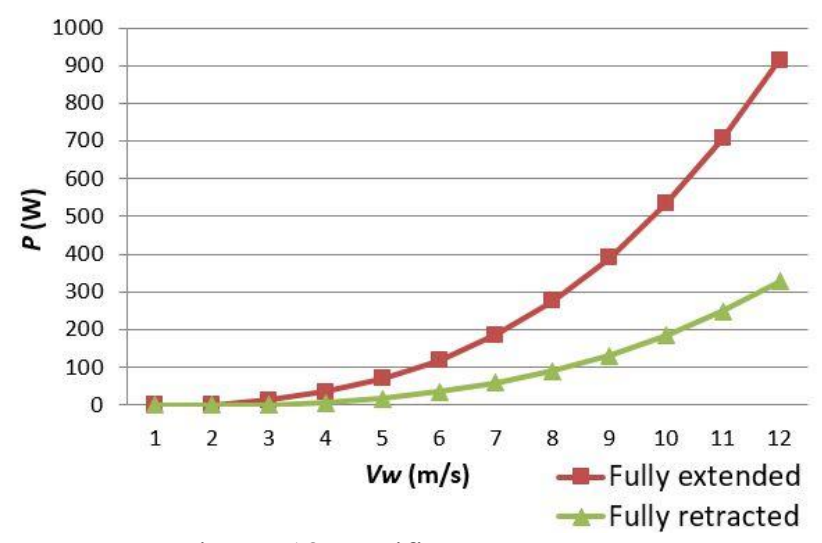

Figure. 13 Rectifier power output

Fig. 11 shows the power curve for variable swept area with three positions. The power output of 900 Watt (red color), 688 Watt (green color), and 276 Watt (blue color) are obtained from the swept area of $1.87 \mathrm{~m}^{2}, 1.24 \mathrm{~m}^{2}$, and $0.82 \mathrm{~m}^{2}$, respectively. It means that the swept area variable can provide constant power output at different wind speed variable through modification of swept area to match with the wind speed.

Fig. 12 shows the VSA rotor performance obtained for different rotations (Rpm) and wind speeds. Every VSA configuration has its own performance characteristic at different rotor speeds. In order to control VAWT, the aerodynamic characteristics for VSA model is defined to select the operating points on which the controller works. The optimum configuration of VSA is adjusted by wind speed clustering as membership function of FLC. During the test, the wind speed is changed at fully retracement and fully extended. The wind speed variation is obtained from 0 to $12 \mathrm{~m} / \mathrm{s}$.

Based on measurement as shown in Fig. 13, the power output is exponential to the wind speed, the higher the wind speed, the higher the power output. It is noted that when the wind speed increases the rotor speed, the power output from VAWT increases at fully extended of VSA, however when the VSA is fully retracted or in minimum position, the power output decreases at the same range of wind speed variation.

In the simulation session as shown Fig.14, VSA testing was conducted using two modes: VSA mode and Fixed Swept Area (FSA) mode. VSA mode is the configuration of appropriate swept area (height and diameter) by FLC to tap constant power when wind speed decreases. FSA mode is a conventional swept area with fixed swept area of which FSA does not have any configuration of the swept area dimension. The measurement of the VSA and FSA performance was tested at the same wind speed from $12 \mathrm{~m} / \mathrm{s}$ to 10 $\mathrm{m} / \mathrm{s}$, respectively. The measurement result is shown in Fig. 14.

The next simulation as shown in Fig. 15 compares VSA to the other paper data [14], in which the paper used fixed swept area with variable pitch control (VPC) using MLP-ANN method. On the other hand, the proposed method uses VSA with control Fuzzy, for fairness comparison, the swept area maximum of VSA dan VPC is of the same value and type (smale 

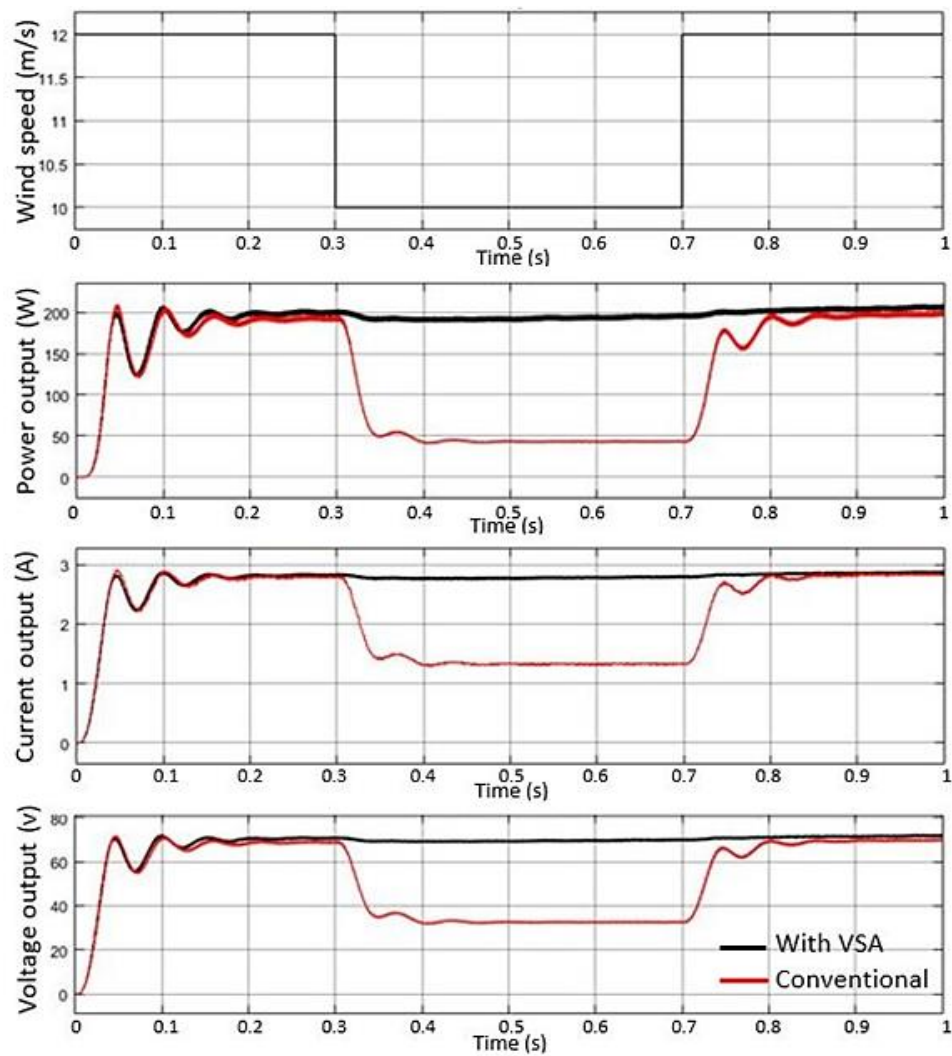

Figure. 14 Performance of the VSA

scale type VAWT). Both, then, were tested at the same wind speed from 12 to $10 \mathrm{~m} / \mathrm{s}$, so that the performance of both methods could be observed as the wind speed was decreased. The result is shown in Fig. 16

\section{Result and discussion}

The performance of the VSA method was simulated using Matlab. An experiment of the VSA method was designed and tested in the laboratory scale, in which the experimental set-up was designed similar to the complete wind power plant.

In the experiment measurement as shown in Fig. 13 , a significant power increase is indicated when the dimension of the swept area was tested on wind speed ranging from $1 \mathrm{~m} / \mathrm{s}$ to $12 \mathrm{~m} / \mathrm{s}$. Based on the measurement, the power output is exponential to the wind speed velocities, the higher the swept area, the higher the power output. When the wind speed reached $12 \mathrm{~m} / \mathrm{s}$, the maximum power of the fully extended VSA is bigger than the fully retracted of $64 \%$. It means that as the sweep area increases, the power output from VAWT increases at full extension of the VSA.

In the simulation session as shown Fig. 14. The VSA was compared to the FSA. The difference VSA and FSA previously described in the experimental set-up section. The VSA is the configuration of appropriate swept area to tap constant power. The FSA is a conventional swept area with fixed swept area. The VSA has been tested with step changes in wind speed velocity that are applied to the VAWT system as shown in Fig. 14. The Fig. 14 shows the performance of the VSA, with the profile of wind speed changes from 12 to $10 \mathrm{~m} / \mathrm{s}$. The VSA with FLC can respond to the wind velocities and generate duty cycle to move the correct VSA position varying the wind speed and tap constant power, while the wind speed keeps changing.

The FSA generates power output proportional to the wind speed; it can be seen at times of $0.3 \mathrm{~s}$, when the wind speed changes from 12 to $10 \mathrm{~m} / \mathrm{s}$, the FSA power output drops from 200 Watt to 50 Watt, while at the same time the VSA method can hold constant power output at 200 Watt. When the wind speed decreases, the VSA is extended to match the power output with the wind speed at times of $0.7 \mathrm{~s}$, the wind speed increases from 10 to $12 \mathrm{~m} / \mathrm{s}$, thus the power output of FSA increases from 50 Watt to 200 Watt. While the VSA is retracted and keeps power output constant at 200 Watt. The VSA can respond to varying wind speeds to achieve rating power and tap constant power. Compared to the FSA, the power output of VSA is better. The FSA generates power output proportional to changes in wind speed; 

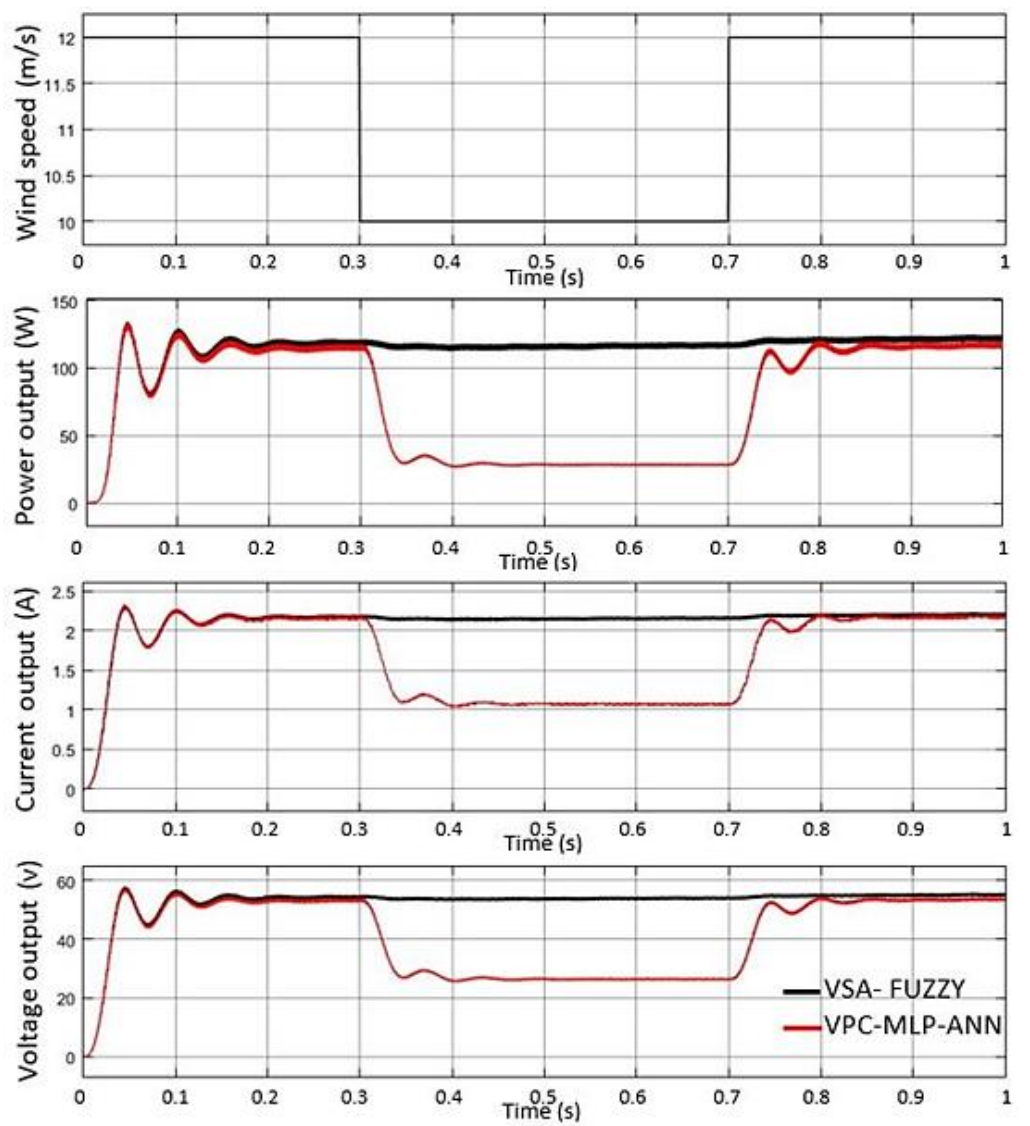

Figure. 15 Comparison performance of the VSA-fuzzy and VPC-MLP-ANN

therefore, power output reduces when the wind velocity decreases from 12 to $10 \mathrm{~m} / \mathrm{s}$. In comparison, the VSA method produces an average output power of 200 Watt, and taps constant voltage at 70 Volts despite the wind speed changes. The result of the VSA method testing shows that the power remains roughly constant as the wind speed changes.

Fig. 15 shows the comparison result between VSA-Fuzzy and other papers using the VPC-MLPANN. The approach between the aforementioned methods and the proposed method has previously been explained in the experimental setup section.

For the simulation, the two methods were tested at the same wind speed using step changes wind speed as in Fig. 15. The result shows that VSA is capable of maintaining constant power when the wind speed is below the wind speed rating at $10 \mathrm{~m} / \mathrm{s}$. For the VPC- MLP-ANN, when the wind speed decreases to $10 \mathrm{~m} / \mathrm{s}$, the method follows the wind movement, hence unable to maintain constant power, and the power output decrease by $75 \%$. When the wind speed is below the wind speed rating, the pitch angle is at the fixed pitch angle of $0^{\circ}$. It is the optimal pitch angle at low wind speed [17] that the wind turbine follows that wind speed pattern; in other words, when below the wind speed rating, as long as using variable pitch control, the turbine remains following the wind movement. Different from the VSA method, when below the wind speed rating, VSA increases the swept area dimension to maintain its constant power. When above the wind speed rating, VSA decreases its dimension to maintain the constant power. The upper and lower limit of wind speed rating is determined based on the wind speed clustering as Fuzzy input, while Fuzzy output is the reference of the swept area. The zone of the wind turbine from cut-in speed, rating wind speed, and cut out speed is divided into five cluster wind speed, and changed into linguistic variable comprising very low, low, rating, strong, and very strong. Thus, VSAfuzzy can respond to wind speed changes to maintain its constant power. The result shows that VSA-fuzzy is far more powerful and generates better performance compared to the VPC-MLP-ANN.

\section{Conclusion}

The performance of VAWT with VSA method has been analyzed in simulation and experiment. It was followed by being compared to other papers using the VPC-MLP-ANN, and tested at the same wind speed from $12 \mathrm{~m} / \mathrm{s}$ to $10 \mathrm{~m} / \mathrm{s}$. When the wind speed was $12 \mathrm{~m} / \mathrm{s}$ on the steady state, both methods indicate constant power of 120 Watts. However, 
when the wind speed was decreased to $10 \mathrm{~m} / \mathrm{s}$, the power in VPC-MLP-ANN decreased drastically from 120 Watts to 29 Watts, decreased by $75 \%$, while VSA-fuzzy only decreased from 120 Watt to 115 Watts, decreased by $4 \%$. It shows that the performance of VSA is far better than VPC-MLPANN at low wind speed. It has been established the VSA system to maintain constant power while wind speed changed. VSA maintained mechanical power on the rotor side using Fuzzy controller, and the converter maintained electrical power output on the generator side with PID controller. These systems showed that the VSA method could hold constant power output at rated value, while wind speed changed. It proves that despite the decreased or increased swept area, the dimension could reach a constant rated power and constant voltage. This system has made VAWT able to operate at wider wind speeds. Future study on this topic is suggested to apply VSA with ANN and other artificial intelligence to increase the performance of VSA being more efficient.

\section{Acknowledgments}

The author would like to thank the Institut Teknologi Sepuluh Nopember and the Politeknik Negeri Banjarmasin for this opportunity, and LPDP for a scholarship. The author also thanks his parents for their support.

\section{References}

[1] O. Zebraoui and M. Bouzi, "Robust sliding mode control based MPPT for a PV/Wind hybrid energy system", International Journal of Intelligent and Systems, Vol. 11, No. 5, pp. 290-300, 2018.

[2] A. Rajagukguk, C. W. Priananda, D. C. Riawan, and M. Ashari, "Prototype of power optimization based on converter topologies reconfiguration using PV string smart clustering method for static miniature photovoltaic farm under partially shaded condition", International Review of Automatic Control, Vol. 10, No. 4, pp. 289-295, 2017.

[3] M. Hossain and M. H. Ali, "Future research directions for the wind turbine generator system", Renewable and Sustainable Energy Reviews, Vol. 49, pp. 481-489, 2015.

[4] D. Hendrawati, A. Soeprijanto, and M. Ashari, "High performance maximum power point tracking on wind energy conversion system", International Journal of Power Electronics and Drive System, Vol. 8, No. 3, pp. 1359-1367,
2017.

[5] C. Galinos, T. J. Larsen, H. A. Madsen, and U. S. Paulsen, "Vertical Axis Wind Turbine Design Load Cases Investigation and Comparison with Horizontal Axis Wind Turbine", Energy Procedia, Vol. 94, No. January, pp. 319-328, 2016.

[6] W. Tjiu, T. Marnoto, S. Mat, M. H. Ruslan, and K. Sopian, "Darrieus vertical axis wind turbine for power generation II: Challenges in HAWT and the opportunity of multi-megawatt Darrieus VAWT development", Renewable Energy, Vol. 75, pp. 560-571, 2015.

[7] L. Battisti, E. Benini, A. Brighenti, S. D. Anna, and M. R. Castelli, "Small wind turbine effectiveness in the urban environment", Renewable Energy, Vol. 129, pp. 102-113, 2018.

[8] P. Jain and A. Abhishek, "Performance prediction and fundamental understanding of small scale vertical axis wind turbine with variable amplitude blade pitching", Renewable Energy, Vol. 97, pp. 97-113, 2016.

[9] S. M. Agravat, N. V. S. Manyam, S. Mankar, and T. Harinarayana, "Theoretical Study of Wind Turbine Model with a New Concept on Swept Area", Energy and Power Engineering, Vol. 7 , pp. 127-134, 2015.

[10] M. Imraan, R. N. Sharma, and R. G. J. Flay, "Wind tunnel testing of a wind turbine with telescopic blades: Theinfluence of blade extension", Energy, Vol. 53, pp. 22-32, 2013.

[11] D. Han, Y. G. Heo, N. J. Choi, S. H. Nam, K. H. Choi, and K. C. Kim, "Design, fabrication, and performance test of a $100-\mathrm{W}$ helical-blade vertical-axis wind turbine at low tip-speed ratio", Energies, Vol. 11, No. 6, pp. 1-17, 2018.

[12] A. H. Nishioka and O. de Almeida, "Study, Design and Test of a LENZ-type Wind Turbine", International Journal of Advanced Engineering Research and Science, Vol. 5, No. 3, pp. 264269, 2018.

[13] L. Zhang, Y. Pei, Y. Liang, F. Zhang, Y. Wang, J. Meng and H. Wang "Design and implementation of straight-bladed vertical axis wind turbine with collective pitch control", IEEE International Conference on Mechatronics and Automation, pp. 1258-1263, 2015.

[14] G. Abdalrahman, W. Melek, and F. S. Lien, "Pitch angle control for a small-scale Darrieus vertical axis wind turbine with straight blades (H-Type VAWT)", Renewable Energy, Vol. 114, pp. 1353-1362, 2017.

[15] B. wu, Y. Lang, N. Zargari, and S. Kouro, 
Power Conversion and Control of Wind Energy Systems, 1st ed., Wiley-IEEE Press, Hoboken, New Jersey, 2011.

[16] T. L. Van and T. Hai, "Advanced Pitch Angle Control Based on Fuzzy Logic for VariableSpeed Wind Turbine Systems", IEEE Transactions on Energy Conversion, Vol. 7, No. 3, pp. 259-266.

[17] Y. Guo, X. Li, L. Sun, Y. Gao, Z. Gao, and L. Chen, "Aerodynamic analysis of a step adjustment method for blade pitch of a VAWT", Journal of Wind Engineering and Industrial Aerodynamics, Vol. 188, No. October 2018, pp. 90-101, 2019.

[18] K. G. Upadhaya, A. Verma, M. M. Tripathi, and R. Kumar, "Design of adjustable blade wind turbine for constant generated power", Proceedings of 6th IEEE Power India International Conference, pp. 1-5, 2015.

[19] S. Watson, A. Moro, V. Reis, C. Baniotopoulos, S. Barth, G. Bartoli, F. Bauer, E. Boelman, D. Bosse, A. Cherubini, A. Croce, L. Fagiano, M. Fontana, A. Gambier, K. Gkoumas, C. Golightly, M. Latour, P. Jamieson, J. Kaldellis, A. Macdonald, J.Murphy, M. Muskulus, F. Petrini, L. Pigolotti, F. Rasmussen, P. Schild, R. Schmehl, N. Stavridou, J. Tande, N. Taylor, T. Telsnig, and R. Wiser, "Future emerging technologies in the wind power sector: A European perspective", Renewable and Sustainable Energy Reviews, Vol. 113, pp. 1-21, 2019.

[20] T. K. Barlas and G. A. M. van Kuik, "Review of state of the art in smart rotor control research for wind turbines", Progress in Aerospace Sciences, Vol. 46, pp. 1-27, 2010.

[21] I. Houtzager, J. W. Van Wingerden, and M. Verhaegen, "Rejection of periodic wind disturbances on an experimental 'smart' rotor section using lifted repetitive control', In: Proc. of the IEEE International Conference on Control Applications, Vol. 21, pp. 264-271, 2011.

[22] J. Fadil, Soedibyo, and M. Ashari, "Performance Analysis of Vertical Axis Wind Turbine with Variable Swept Area", International Seminar on Intelligent Technology and Its Application, pp. 217-221, 2017.

[23] H. Kala and K. S. Sandhu, "Effect of change in power coefficient on the performance of wind turbines with different dimensions", In: Proc. of International Conference on Micro Electronics, Computing and Communication, pp. 1-4, 2016.

[24] L. Wang, L. Cao, and L. Zhao, "Non-linear tip speed ratio cascade control for variable speed high power wind turbines: A backstepping approach", IET Renewable Power Generation, Vol. 12, No. 8, pp. 968-972, 2018.

[25] Venkata, Yaramu, and B. Wu, Model predictive control of wind energy conversion systems, 1st ed., Wiley-IEEE Press, Piscataway, New Jersey, 2017.

[26] P. M. Kumar, K. R. Ajit, M. R. Surya, N. Srikanth, and T. Lim, "On the self starting of Darrieus turbine: An Experimental investigation with secondary rotor", In : Proc. of the 2017 Asian Conference on Energy, Power and Transportation Electrification, pp. 1-7, 2017.

[27] A. Naseem, E. Uddin, Z. Ali, J. Aslam, S. R. Shah, M. Sajid, A. A. Zaidi, A. Javed, M. Y. Younis., "Effect of vortices on power output of vertical axis wind turbine (VAWT)", Sustainable Energy Technologies and Assessments, Vol. 37, pp. 1-11, 2020.

[28] J. Zwierzchowski, P. A. Laski, S. Blasiak, J. E. Takosoglu, D. S. Pietrala, G. F. Bracha and L. Nowakowski., "Model tests of wind turbine with a vertical axis of rotation type Lenz 2", In: Proc. of EPJ Web of Conferences, Vol. 143, 2017.

[29] W. T. Chong, M. Gwani, S. Shamshirband, W. K. Muzammil, and C. J. Tan, "Application of adaptive neuro-fuzzy methodology for performance investigation of a poweraugmented vertical axis wind turbine", Energy, Vol. 102, pp. 630-636, 2016.

[30] W. Tjiu, T. Marnoto, S. Mat, M. H. Ruslan, and K. Sopian, "Darrieus vertical axis wind turbine for power generation I: Assessment of Darrieus VAWT configurations", Renewable Energy, Vol. 75, pp. 50-67, 2015.

[31] A. Ghani, A. Tahour, M. Abid, and F. Nollet, "Power Control of Wind Turbine based on Fuzzy Controllers", Energy Procedia, Vol. 42, pp. 163-172, 2013.

[32] P. Lap-Arparat and T. Leephakpreeda, "Realtime maximized power generation of vertical axis wind turbines based on characteristic curves of power coefficients via fuzzy pulse width modulation load regulation", Energy, Vol. 182, pp. 975-987, 2019.

[33] A. Hossain, R. Singh, I. A. Choudhury, and A. Bakar, "Energy efficient wind turbine system based on fuzzy control approach", Procedia Engineering, Vol. 56, pp. 637-642, 2013.

[34] E. H. Dursun and A. Durdu, "Position control by using PD type fuzzy logic: Experimental study on rotary servo system", In: Proc. of the 8th 
International Conference on Electronics, Computers and Artificial Intelligence, pp. 11-16, 2017.

[35] S. K. Raju and G. N. Pillai, "Design and implementation of type-2 fuzzy logic controller for DFIG-based wind energy systems in distribution networks", IEEE Transactions on Sustainable Energy, Vol. 7, No. 1, pp. 345-353, 2016.

[36] J. Liu, Y. Gao, S. Geng, and L. Wu, "Nonlinear Control of Variable Speed Wind Turbines via Fuzzy Techniques", IEEE Access, Vol. 5, pp. 27-34, 2017.

[37] R. I. Putri, M. Pujiantara, A. Priyadi, T. Ise, and M. H. Purnomo, "Maximum power extraction improvement using sensorless controller based on adaptive perturb and observe algorithm for PMSG wind turbine application", IET Electric Power Applications, Vol. 12, No. 4, pp. 455462, 2018.

[38] M. K. Nguyen, T. D. Duong, Y. C. Lim, and Y. J. Kim, "Isolated Boost DC-DC Converter with Three Switches", IEEE Transactions on Power Electronics, Vol. 33, No. 2, pp. 1389-1398.

[39] S.-W. Seo and H. H. Choi, "Digital Implementation of Fractional Order PID-Type Controller for Boost DC-DC Converter", IEEE Access, Vol. 7, pp. 142652-142662, 2019.

[40] A. K. Chauhan, M. Raghuram, and S. K. Singh, "Extended boost three phase matrix converter using switched capacitor topology having buck boost ability", In: Proc. of IEEE International Conference on Power Electronics, Drives and Energy Systems, pp. 1-4, 2017.

[41] M. Rahimi, "Modeling, control and stability analysis of grid connected PMSG based wind turbine assisted with diode rectifier and boost converter", International Journal of Electrical Power and Energy Systems, Vol. 93, pp. 84-96, 2017.

[42] N. Rana, M. Kumar, A. Ghosh, and S. Banerjee, "A Novel Interleaved Tri-State Boost Converter with Lower Ripple and Improved Dynamic Response", IEEE Trans. Ind. Electron., Vol. 65, No. 7, pp. 5456-5465, 2018.

[43] H. Liu, Y. Ji, L. Wang, and P. Wheeler, "A family of improved magnetically coupled impedance network boost DC-DC converters", IEEE Transactions on Industrial Electronics, Vol. 33, No. 5, pp. 3697-3702, 2018.

[44] A. S. Wardhana, "Optimal Control of Robotic Arm System to Improve Flux Distribution on Dual Parabola Dish Concentrator", International Journal of Intelligent Engineering and Systems, Vol. 13, No. 1, pp. 364-378, 2020. 